\title{
Rabid dog illegally imported to France from Morocco, August 2011
}

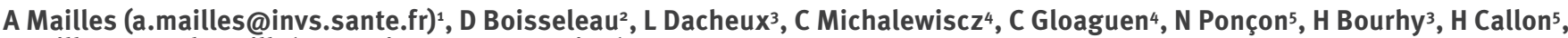
V Vaillant ${ }^{1}$, I Dabosville ${ }^{6}$, P Morineau-Le Houssine $^{6}$

1. French Institute for Public Health Surveillance (Institut de Veille Sanitaire, InVS), Saint Maurice, France

2. Regional Office for veterinary services Vendée (Direction départementale de la protection des populations de Vendée), La Roche sur Yon, France

3. Institut Pasteur, National Reference Centre for Rabies, Paris, France

4. Regional Agency for Health Pays de Loire, Nantes, France

5. General Directorate for Food (Direction Générale de l'Alimentation), Ministry of Agriculture, Paris, France

6. Anti-rabies Centre, University Hospital (Centre antirabique, centre hospitalier universitaire), Nantes, France

Mailles A, Boisseleau D, Dacheux L, Michalewiscz C, Gloaguen C, Ponçon N, Bourhy H, Callon H, Vaillant V, Dabosville I, Morineau-Le Houssine P. Rabid dog illegally imported to France from Morocco, August 2011.

Euro Surveill. 2011;16(33):pii=19946. Available online: http://www.eurosurveillance.org/ViewArticle.aspx?Articleld=19946

Article published on 18 August 2011

In August 2011, a case of canine rabies was notified to the French veterinary services. The dog was a threemonth-old puppy illegally imported from Morocco that presented behavioural changes on 1 August and was admitted to a veterinary clinic on 6 August. It died the following day and the body was shortly sent to the national reference centre where rabies was laboratory-confirmed on 11 August. Contact tracing and postexposure treatment were initiated immediately.

A suspected case of canine rabies was notified to the official veterinary services (Direction Départementale de la Protection des Populations, DDPP) of the district of Vendée, France, on 6 August 2011. The dog was a threemonth-old Jack-Russell-type puppy that presented with behavioural changes consisting of progressive sleepiness on 1 August and later, with aggressiveness. The dog was admitted to a veterinary clinic on 6 August and died the following day. Rabies was suspected on admission, and the dog's body was sent shortly after death to the National Reference Centre for Rabies (Institut Pasteur, Paris, France) for biological diagnosis, where rabies was confirmed one day after receipt, on 11 August, by direct immunofluorescence and by virus isolation in tissue culture. The detection of viral RNA by RT-hemi-nested PCR and by real-time PCR was also positive. The viral strain was identified as a lyssavirus belonging to Rabies virus species (formerly genotype 1), Africa 1 lineage and genetically closely related to strains isolated in Morocco [1].

\section{Investigation of potential risk to \\ human and animal health}

Taking into account the date of onset of signs and the date of death, the maximum viral excretion period, and thus the potential risk of infection transmission, was considered ranging from 18 July to 7 August.

The owners of the dog were a French family who spent holidays in Morocco. They found and adopted the stray dog near Rabat on 11 July 2011. The dog stayed with the family in Morocco until they left on 31 July. They travelled back to France with the dog by car and ferryboat. The dog was not vaccinated against rabies (and was too young to be vaccinated and imported according to European regulations [2]) and was not micro chipped. Conditions required for importation of dogs and entry into the European Union (EU) were not respected [2].

The family drove through Spain during the night without stopping except for fuel and crossed the SpanishFrench border on 1 August. In France, the dog did not wander unsupervised but was presented by a child of the family to several persons among her social contacts.

The family members were interviewed by the regional health authorities (ARS) and the DDPP in order to list all known persons and animals that had had direct contact with the dog in France, Spain and Morocco. All persons identified in France were contacted by the physician in charge from the anti-rabies clinic at the university hospital in Nantes to evaluate their individual risk of contamination with regards to the nature and date of contacts, according to World Health Organization (WHO) recommendations [3].

\section{Contact tracing and control measures}

In France, three of eight family members who had contact with the dog were considered as category III exposure according to the WHO criteria. All three had been bitten, had transdermal wounds and received postexposure treatment (PET) consisting of vaccination and rabies immunoglobulin [3].

A total of 19 people among social contacts of the family reported direct contact with the dog. One reported having been bitten and received vaccination and rabies immunoglobulin. A second person had been licked on non-intact skin (skin lesions) and received vaccination 
only. Seventeen persons had only category I exposures and did not receive PET [3]. The veterinarian who took care of the dog had previously been vaccinated and therefore only received a booster vaccination. The veterinary nurse who had category I exposures did not receive $\mathrm{PET}$.

No persons had direct contact with the dog in Spain, whereas some relatives and friends in Morocco were identified with at-risk exposures. Health authorities in Morocco were informed and the contact details of the persons affected provided to make sure they would be taken care of. In total, 29 people had direct contacts and six received PET (Table 1).

Another dog, one cat and two kittens had direct contact with the dog at the place of residence of the family in France. The dog was identified by microchip and had previously been vaccinated against rabies. Following the exposure to the rabid puppy, it received a booster vaccination according to French regulations. The cat and both kittens had not been vaccinated nor micro chipped before the contact with the dog and were

\section{TABLE 1}

At-risk exposure to the rabid dog and management of patients, France, August 2011

\begin{tabular}{|l|c|c|c|c|}
\hline Exposure category & $\begin{array}{c}\text { Category } \\
1\end{array}$ & $\begin{array}{c}\text { Category } \\
2\end{array}$ & $\begin{array}{c}\text { Category } \\
3\end{array}$ & Total \\
\hline Family members & 5 & 0 & $3^{\mathrm{b}}$ & 8 \\
\hline Veterinary staff & 1 & 0 & $1^{\mathrm{c}}$ & 2 \\
\hline Social contacts & 17 & $1^{\mathrm{c}}$ & $1^{\mathrm{b}}$ & 19 \\
\hline Total & 23 & 1 & 5 & 29 \\
\hline
\end{tabular}

${ }^{a}$ According to the World Health Organization criteria [3].

${ }^{b}$ These cases received post-exposure treatment consisting of vaccination and immunoglobulin.

c These cases received post-exposure treatment consisting of vaccination. therefore killed humanely according to the regulations in place.

\section{Discussion and conclusion}

No autochthonous human rabies case has occurred in mainland France since 1923. In 2001, France was declared rabies-free for non-flying terrestrial mammals (based on World Organisation for Animal Health (OIE) criteria), following the elimination of fox rabies in 1998. In 2008, the importation of a rabid dog from Morocco resulted in a chain of transmission of canine rabies in France and the loss of the rabies-free status [4]. However, France regained its rabies-free status according to OIE criteria in February 2010 [5].

Since 2001, nine rabid dogs have been illegally introduced in France (Table 2). All but one had been imported from Morocco through Spain. Before the episode described in this report, the most recent case was an adult dog imported from the Gambia to Belgium, and later to France from Belgium. The number of people who received PET after exposure to one of these nine dogs ranged from two to 187 per episode.

Importations in 2004 and 2008 resulted in a high number of post-exposure treatments administered. In 2004, a rabid dog was brought to music and theatre festivals in south western France where 65,000 festival participants were present.A total of 187 people subsequently received PET through a number of anti-rabies clinics in France $[6,7]$.

In 2008, following the secondary transmission of rabies from an imported infected dog, 152 children had to be vaccinated after a rabid dog contaminated in France wandered into a school yard [6].

More recently in 2008, a puppy was found and adopted in Spain by French tourists who had not travelled outside the EU. The rabies strain later isolated from the dog was genetically closely-related to isolates collected

\section{TABLE 2}

Rabid animals illegally imported to France, 2001-2011

\begin{tabular}{|l|c|c|c|}
\hline Year & French district & Rabid animal & Country of origin \\
\hline 2001 & Gironde & Puppy & Morocco \\
\hline 2002 & Seine Saint Denis & Puppy & Morocco \\
\hline 2004 & Finistère & Adult dog & Morocco \\
\hline 2004 & Gironde & Puppy & Morocco \\
\hline 2004 & Gironde & Adult dog & Morocco \\
\hline 2008 & Seine-et-Marne & Adult dog & Gambia \\
\hline 2008 & Var & Adult dog & Spain \\
\hline 2008 & Isère & Puppy & 152 ${ }^{\text {c }}[4]$ \\
\hline 2011 & Vendée & Puppy & Morocco \\
\hline
\end{tabular}

PET: Post-exposure treatment.

a Two generations of canine transmission occurred after the importation of the rabid dog. The third case was responsible for most of the human exposures.

b Some people exposed in Belgium were taken care of in Brussels.

c This dog was found on the highway in southern Spain. The virus was related to Moroccan strains. 
in the north of Morocco and in Melilla, an autonomous city of Spain located on the African Mediterranean coast, bordering with Morocco. However, it was not possible to determine whether the dog was directly imported into Spain from these regions during its incubation period or if it was secondarily infected in Spain by another infected animal imported from Morocco or Mellila [8].

These reports illustrate how illegally imported dogs are a health risk in otherwise rabies-free regions and pose an unnecessary strain on the health system due to the required contact tracing. Furthermore, they emphasise the risk of re-introduction and diffusion of the disease in rabies-free countries. Travellers should be informed of animal importation regulations and of the risk of being infected through bites from animals who may present with normal behaviour in the early stages of infection.

The suspicion and identification of rabies in the case described in the current report was carried out early thanks to the awareness of the veterinarian faced with a puppy displaying abnormal behaviour and a history of recent importation from an enzootic country.

Despite the rabies-free status, the maintenance of epidemiological surveillance and medical knowledge both on the human and veterinarian aspects remains critical to insure early recognition of the disease, identification of human and animal at-risk exposure, avoid uncontrolled secondary transmission and implement PET in at-risk people.

\section{References}

1. Talbi C, Lemey P, Suchard MA, Abdelatif E, Elharrak M, Nourlil $J$, et al. Phylodynamics and human-mediated dispersal of a zoonotic virus. PLoS Pathog. 2010;6(10):e1001166.

2. European Parliament and Council of the European Union. Regulation (EC) No 998/2003 on the animal health requirements applicable to the non-commercial movement of pet animals and amending Council Directive 92/65 EEC. 13 Jun 2003. Available from: http://eur-lex.europa.eu/LexUriServ/ LexUriServ.do?uri=0J:L:2003:146:0001:0009:EN:PDF

3. World Health Organization (WHO). Rabies vaccines : WHO position paper. Wkly Epidemiol Rec. 2010;85(32):309-14. Available from: http://www.who.int/wer/2010/wer8532.pdf

4. French multidisciplinary investigation team. Identification of a rabid dog in France illegally introduced from Morocco. Euro Surveill. 2008;13(11):pii=8066. Available from: http://www. eurosurveillance.org/ViewArticle.aspx?Articleld=8066

5. Self declaration by France on the recovery of its rabies-free status. [Access 17 Aug 2011]. Available from: http://www.oie. int/doc/ged/D9588.PDF

6. Servas V, Mailles A, Neau D, Castor C, Manetti A, Fouquet $\mathrm{E}$, et al. An imported case of canine rabies in Aquitaine: Investigation and management of the contacts at risk, August 2004-March 2005. Euro Surveill. 2005;10(11): pii $=578$. Available from: http://www.eurosurveillance.org/ViewArticle. aspx?Articleld $=578$

7. Lardon Z, Watier L, Brunet A, Bernède $C$, Goudal $M$, Dacheux L, et al. Imported episodic rabies increases patient demand for and physician delivery of antirabies prophylaxis. PLoS Negl Trop Dis. 2010;4(6):e723.

8. French Institute for Public Health Surveillance (Institut de Veille Sanitaire, InVS). [Case of canine rabies imported to Isère]. Saint-Maurice: InVS. 26 Nov 2008. French. Available from http://www.invs.sante.fr/surveillance/rage/default.htm 